\title{
Influência da Temperatura Ambiente sobre o Desempenho e os Parâmetros Fisiológicos de Suínos Machos Castrados dos 30 aos 60 kg $^{1}$
}

\section{Sandra Lúcia da Silva Tavares ${ }^{2}$, Juarez Lopes Donzele ${ }^{3}$, Rita Flávia Miranda de Oliveira ${ }^{3}$, Aloízio Soares Ferreira ${ }^{3}$}

\begin{abstract}
RESUMO - O presente trabalho foi realizado para avaliar a influência de ambientes térmicos constantes (termoneutro e calor) sobre o desempenho e as variáveis fisiológicas de suínos machos castrados dos 30 aos $60 \mathrm{~kg}$ PV. Cem animais foram distribuídos em delineamento em blocos ao acaso, com cinco tratamentos $(3100,3250,3400,3550$ e $3700 \mathrm{kcal}$ de ED/kg de ração), cinco repetições e dois animais por unidade experimental. Ganho de peso, consumo de ração, proteína e energia, conversão alimentar e eficiência de utilização da proteína e da energia foram reduzidos no ambiente de calor. A relação peso jejum/peso vivo foi maior no ambiente de calor e a relação peso carcaça/peso jejum não foi influenciada pela temperatura ambiente. A taxa de deposição de proteína elevou e a de gordura decresceu com o aumento da temperatura no ambiente. A temperatura ambiente reduziu o peso dos órgãos internos e aumentou a freqüência respiratória, nos animais mantidos no ambiente de calor. Embora a conversão alimentar tenha piorado no ambiente de calor, os animais mantidos neste ambiente apresentaram maior taxa de deposição de proteína na carcaça.
\end{abstract}

Palavras-chave: composição de carcaça, desempenho, estresse de calor, órgãos internos, suínos em crescimento, termoneutro

\section{Influence of Environment Temperature on the Performance and the Physiological Traits of Barrows from 30 to $60 \mathrm{~kg}$}

\begin{abstract}
The present work was conducted to evaluate the effect of constant thermal environment on the performance and physiological traits of barrows from 30 to $60 \mathrm{~kg} \mathrm{LW}$. A total of 100 animals were allotted to a randomized block design, with five treatments $(3100,3250,3400,3550$ and $3700 \mathrm{kcal}$ of DE/kg of diet), five replicates and two animals per experimental unit. Weight gain, intakes of diet, protein and energy and feed:gain ratio and the efficiencies of protein and energy utilization were reduced in the heat environment. Fast weight/live weight ratio was higher in the heat environment and the environment temperature did not affect the carcass weight/fast weight ratio. The protein deposition rate increased and the fat deposition rate decreased as the environment temperature increased. The environment temperature reduced the internal organ weight and increased the respiratory frequency, in the animals maintained under heat. Although feed:gain ratio had decreased in the heat environment, the animals maintained in this environment presented higher protein deposition rate in the carcass.
\end{abstract}

Key Words: thermoneutral, heat stress, growing swine, performance, internal organs, carcass

\section{Introdução}

A resposta dos suínos ao estresse de calor consiste, principalmente, na intensificação da dissipação de calor por evaporação pelo trato respiratório, seguida da redução no consumo de alimentos, com conseqüente redução na ingestão de energia e na atividade da tireóide, constituindo um esforço do animal em reduzir a produção de calor metabólico (BIANCA, 1968; FIALHO, 1994).

Essas respostas fisiológicas e metabólicas resultam em menor taxa de crescimento, reduzida eficiência de utilização do alimento e alterações na composição de carcaça. Assim, para garantir o atendimento das exigências nutricionais, deve-se aumentar os níveis dos nutrientes nas rações para os animais expostos ao calor, modificando-se a densidade energética da ração.

Diversos autores (STAHLY e CROMWELL, 1979; JENSEN, 1991; SCHENCK et al., 1992; FIALHO, 1994; e OLIVEIRA et al., 1997) têm relatado o benefício da incorporação de óleo às rações, em razão de seu baixo incremento calórico e alta densidade energética, para amenizar os efeitos do calor sobre os suínos.

Um dos ajustes fisiológicos observados em suínos expostos ao calor consiste na redução do peso de órgãos internos (DAUNCEY et al., 1983; OLIVEIRA et al., 1997), associada à redução no consumo de alimentos.

O presente trabalho foi conduzido com o objetivo

\footnotetext{
${ }^{1}$ Parte da Tese de Doutorado do primeiro autor- Projeto financiado pela FAPEMIG

${ }^{2}$ Aluno do curso de Doutorado, DZO - UFV.

3 Professor do DZO - UFV.
} 
de avaliar a influência de ambientes térmicos constantes (termoneutro e calor) sobre o desempenho e as variáveis fisiológicas de suínos machos castrados dos 30 aos $60 \mathrm{~kg}$ de peso, consumindo rações contendo diferentes níveis de energia.

\section{Material e Métodos}

Oexperimento foi conduzido no Setorde Suinocultura do Departamento de Zootecnia da Universidade Federal de Viçosa (UFV), em Viçosa, MG.

Foram utilizados dados de 100 suínos machos castrados, 50 mantidos em ambiente de termoneutralidade e $50 \mathrm{em}$ ambiente de estresse de calor, mestiços, com pesos iniciais médios de 30,5 $\pm 2,08$ $\mathrm{kg} \mathrm{e} 30,7 \pm 1,36 \mathrm{~kg}$, respectivamente. Em cada ambiente, os animais foram distribuídos em delineamento de blocos ao acaso, com cinco repetições e dois animais por unidade experimental, recebendo rações experimentais com cinco diferentes níveis de energia digestível (3100, 3250, 3400, 3550 e 3700 kcal de ED/ $\mathrm{kg}$ de ração). Na formação dos blocos, adotou-se o critério de peso inicial e grau de parentesco.

A temperatura média interna da sala foi mantida por meio de um conjunto de seis aquecedores, tipo campânula de resistência, ligados a um termostato regulado para a temperatura de $32^{\circ} \mathrm{C}$, no ambiente de calor, e com dois aparelhos de ar-condicionado ligados a um termostato regulado para a temperatura de $22^{\circ} \mathrm{C}$, no ambiente de termoneutralidade

Os termostatos e os equipamentos de medição ambiental (termômetros de bulbo seco e bulbo úmido, de máxima e mínima e de globo negro) foram instalados em uma gaiola vazia no centro da sala a uma altura correspondente à do animal. As leituras dos instrumentos foram realizadas às 8 e $16 \mathrm{~h}$, diariamente.

As condições térmicas médias da sala durante os períodos experimentais foram: $21,3 \pm 1,04^{\circ} \mathrm{C}$ e $32,0 \pm 0,88^{\circ} \mathrm{C}$ de temperatura do ar; $61,8 \pm 2,64 \%$ e $76,7 \pm 5,39 \%$ de umidade relativa do ar; $21,7 \pm 0,97^{\circ} \mathrm{C}$ e $31,8 \pm 2,00^{\circ} \mathrm{C}$ de temperatura de globo negro; e $69 \pm 1,19$ e $83 \pm 2,14$ de índice de temperatura de globo e umidade, respectivamente, nos ambientes de termoneutralidade e calor.

Uma vez a cada semana, em ambos os experimentos, foram feitas as medidas de temperatura retal, pela manhã $(8 \mathrm{~h})$ e à tarde $(15 \mathrm{~h})$, e freqüência respiratória dos animais, às $8 \mathrm{~h}$. A temperatura retal foi medida por meio de um termômetro clínico, introduzido no reto de cada animal durante 1 minuto. A freqüência respiratória foi obtida pela contagem dos movimentos do flanco dos animais durante 30 segundos e o resultado foi multiplicado por dois para obter os dados em minutos.

As rações experimentais (Tabela 1) e a água foram fornecidas à vontade. As sobras de ração foram pesadas semanalmente. Os animais foram pesados no início e final dos experimentos, quando atingiram, em média, $60,1 \pm 3,91 \mathrm{~kg}$ e $59,9 \pm 3,23 \mathrm{~kg}$, respectivamente, no ambiente de 21 e $32^{\circ} \mathrm{C}$, para determinação das variáveis de desempenho.

Ao final dos experimentos, todos os animais, em ambos os ambientes, foram submetidos a jejum de 24 horas, quando foram novamente pesados e abatidos. Após o abate, as carcaças depiladas e evisceradas foram pesadas, sendo que a metade direita das carcaças foram trituradas, por 15 minutos, em "cutter" comercial de 30HP e 1775 revoluções por minuto. O abate e o processamento das carcaças, para obtenção das amostras, foram realizados de acordo com metodologia descrita por DONZELE et al. (1992).

Comparando-se os resultados de composição de proteína e gordura das carcaças dos animais em experimento com os resultados de carcaça de um grupo adicional de dez leitoas -cinco com peso médio de $31,0 \pm 0,86 \mathrm{~kg}$ e cinco com $30,2 \pm 0,92 \mathrm{~kg}$-, respectivamente, para o ambiente termoneutro e quente, foram determinadas as taxas de deposição de proteína e gordura na carcaça, para cada ambiente.

As amostras das carcaças foram pré-secas em estufa de ventilação forçada a $\pm 60^{\circ} \mathrm{C}$ por 96 horas e pré-desengorduradas pelo método a quente no extrator tipo "Soxhlet", durante 5 horas, para posterior análise de gordura e proteína, conforme metodologia descrita por SILVA (1990).

Após o abate, foram retirados fígado, pulmões, estômago, rins, coração e intestino delgado, que foram lavados e dependurados em ganchos, à sombra, para, depois de escorrido bem o sangue, se proceder à pesagem.

As análise estatísticas das variáveis de desempenho, das taxas de deposição de proteína e gordura nas carcaças, dos pesos dos órgãos e dos parâmetros fisiológicos foram realizadas por intermédio do programa ANOVAG, contido no pacote computacional SAEG (Sistema para Análises Estatísticas e Genéticas), desenvolvido pela UFV (1982).

\section{Resultados e Discussão}

Os resultados de desempenho, consumos de proteína e energia digestível de suínos machos castrados dos 30 aos $60 \mathrm{~kg}$ de peso são mostrados na Tabela 2. 
Rev. bras. zootec.

Tabela 1 - Composição das dietas experimentais (\%)

Table 1 - Composition of experimental diets

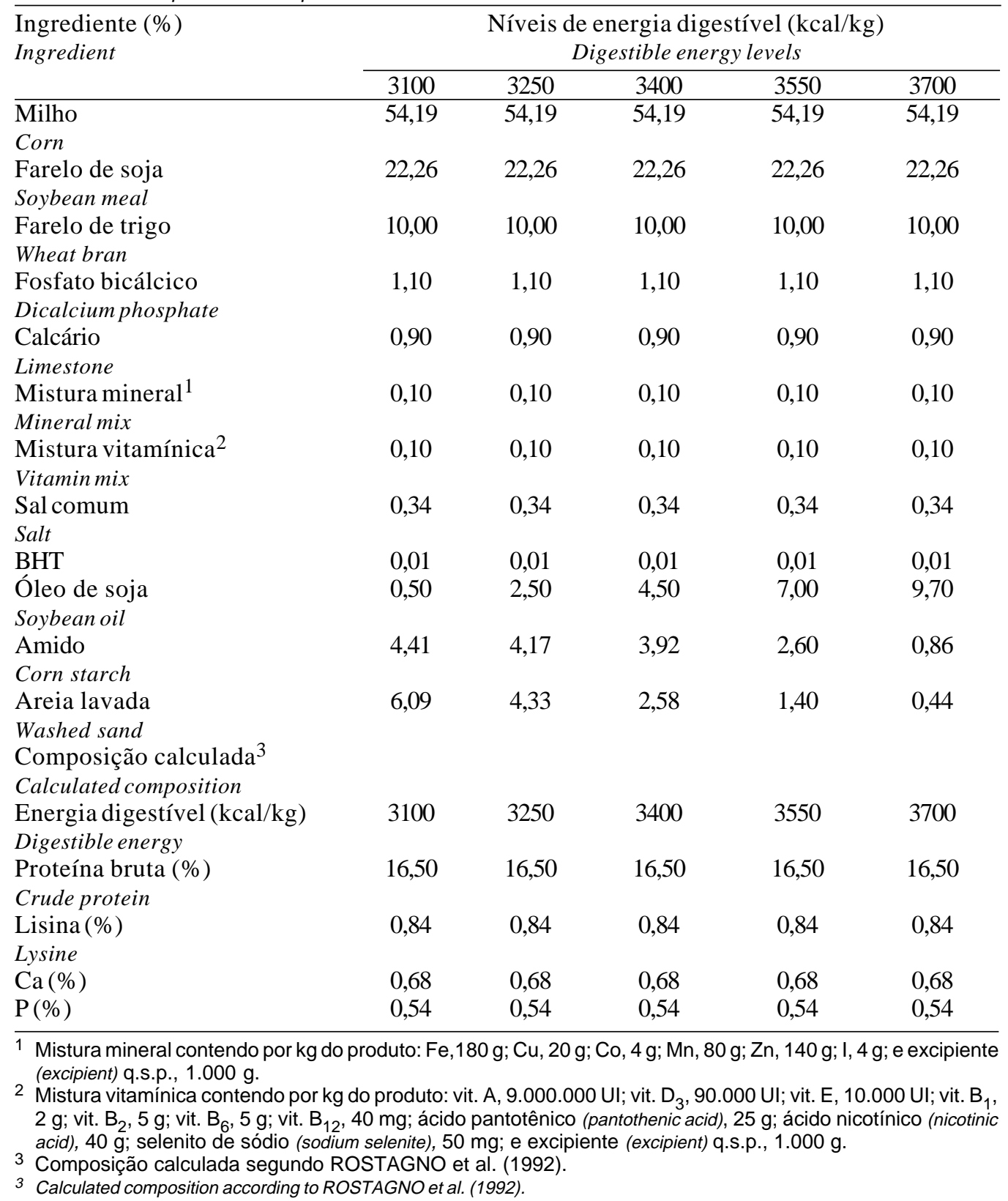

Não foi observado efeito de interação entre a temperatura ambiente e os níveis de ED da ração. Observou-se que a temperatura ambiente de $32^{\circ} \mathrm{C}$ reduziu $(\mathrm{P}<0,01)$ em 17,5 e $13,4 \%$ o ganho de peso diário (GPD) e o consumo de ração (CR), respectivamente. Estes resultados assemelham-se aos obtidos por STAHLY e CROMWELL (1979), STAHLY et al. (1979), DIVIDICH e NOBLET (1986), LOPEZ et al. (1991), SCHENCK et al. (1992) e OLIVEIRA et al. (1997), que verificaram redução no ganho de peso diário e consumo de ração de suínos, em diferentes fases de crescimento, expostos ao calor.

Diferentes autores (STAHLY et al., 1979; FIALHO, 1994; e FORBES, 1995) relataram que os suínos, quando submetidos a estresse térmico de calor, reduzem o consumo voluntário de alimentos e, por conseguinte, a taxa de crescimento, como forma de reduzir a quantidade de calor proveniente de processos digestivos e metabólicos.

Foi verificado que a conversão alimentar (CA) piorou $(\mathrm{P}<0,01)$ nos animais mantidos no calor em relação ao ambiente termoneutro, evidenciando que ocorreu menor eficiência de utilização do alimento com o aumento de temperatura, o que proporcionou, associado ao menor consumo de ração, redução no GPD destes animais. STAHLY e CROMWELL (1979) e CHRISTON (1988) também constataram piora na eficiência de utilização do alimento em 
Tabela 2 - Desempenho, consumos de energia digestível e proteína e eficiências de utilização da proteína e energia de suínos machos castrados dos 30 aos $60 \mathrm{~kg}$

Table 2 - Performance, digestible energy and protein intakes and protein and energy efficiency of utilization of barrows from 30 to $60 \mathrm{~kg}$

\begin{tabular}{lccc}
\hline & \multicolumn{3}{c}{ Temperatura ambiente $\left({ }^{\circ} \mathrm{C}\right)$} \\
Environment temperature \\
\cline { 2 - 4 } $\begin{array}{l}\text { Variável } \\
\text { Variable }\end{array}$ & 21 & 32 & $\alpha$ \\
\hline $\begin{array}{l}\text { Ganho de peso (g/dia) } \\
\text { Weight gain (g/day) }\end{array}$ & $884 \pm 71,16$ & $729 \pm 38,67$ & 0,01 \\
$\begin{array}{l}\text { Consumo de ração (g/dia) } \\
\text { Feed intake (g/day) }\end{array}$ & $2172 \pm 250,42$ & $1880 \pm 127,23$ & 0,01 \\
$\begin{array}{l}\text { Conversão alimentar (g/g) } \\
\text { Feed:gain ratio }\end{array}$ & $2,46 \pm 0,24$ & $2,58 \pm 0,19$ & 0,01 \\
$\begin{array}{l}\text { Consumo de energia (kcal/dia) } \\
\text { Energy intake (kcal/day) }\end{array}$ & $7358 \pm 729,40$ & $6392 \pm 425,57$ & 0,01 \\
$\begin{array}{l}\text { Consumo de proteína (g/dia) } \\
\text { Protein intake (g/day) }\end{array}$ & $358 \pm 41,32$ & $310 \pm 20,99$ & 0,01 \\
$\begin{array}{l}\text { Eficiência de utilização da proteína } \\
\text { Efficiency of protein utilization }\end{array}$ & $0,41 \pm 0,04$ & $0,43 \pm 0,03$ & 0,01 \\
$\begin{array}{l}\text { Eficiência de utilização da energia } \\
\text { Efficiency of energyutilization } \\
\text { CPD/TDP }\end{array}$ & $8,33 \pm 0,55$ & $8,77 \pm 0,39$ & 0,01 \\
\hline
\end{tabular}

suínos em crescimento, mantidos em ambiente de alta temperatura. No entanto, STAHLY et al. (1979), SCHENCK et al. (1992) e OLIVEIRA et al. (1997) não observaram variação na CA de suínos, em razão da temperatura ambiente.

A redução $(\mathrm{P}<0,01)$ observada nos consumos de energia digestível (CED) e proteína (CPD) diários dos animais expostos à temperatura de $32^{\circ} \mathrm{C}$ ocorreu em razão do menor consumo de ração.

Conforme observado na conversão alimentar, as eficiências de utilização da energia e proteína, expressas como as quantidades de CED e CPD por grama de ganho de peso, foram influenciadas $(\mathrm{P}<0,01)$ pela temperatura ambiente, com aumento de 5,3 e $4,9 \%$ no ambiente quente, respectivamente (Tabela 2). Diversos autores, citados por STAHLY e CROMWELL (1979), relataram que a pior eficiência de utilização da energia observada em leitões mantidos em ambiente quente pode ser atribuída a aumento nos requerimentos de mantença e à redução no consumo de energia.

Os resultados de eficiência de utilização de energia são similares aos observados para suínos em crescimento (STAHLY e CROMWELL, 1979) e desmamados (DIVIDICH e NOBLET, 1986) e os de eficiência de utilização de proteína, aos observados por LOPEZ et al. (1994), para leitoas em terminação. Entretanto, STAHLY e CROMWELL (1986) e OLIVEIRA et al. (1997), trabalhando com suínos em crescimento e leitões dos 15 aos $30 \mathrm{~kg}$, respectivamente, não observaram variação nas eficiências de utilização da energia e proteína.

Avaliando a relação CPD/TDP (quantidades de CPD por grama de proteína depositada), observou-se melhora $(\mathrm{P}<0,01)$ de $31 \%$ na eficiência de utilização da proteína para deposição de proteína na carcaça dos animais submetidos à temperatura ambiente de $32^{\circ} \mathrm{C}$. A redução na exigência de proteína para mantença de animais mantidos no calor, provavelmente, explica este resultado. Segundo estimativa de CLOSE et al.(1978), as exigências de proteína para mantença reduziram de 3,35 para $0,82 \mathrm{~g} / \mathrm{kg}^{0,75}$. dia para suínos dos 21 aos $38 \mathrm{~kg}$, mantidos à temperatura de 20 e $30^{\circ} \mathrm{C}$, respectivamente.

Não se observou efeito de interação entre temperatura ambiente e níveis de ED da ração, para os resultados apresentados na Tabela 3. Contudo, a temperatura ambiente influenciou $(\mathrm{P}<0,01)$ a relação peso de jejum/peso vivo (PJ/PV) dos animais, mas não causou variação na relação peso de carcaça/ peso de jejum (PC/PJ).

Os animais mantidos em temperatura ambiente de $32^{\circ} \mathrm{C}$ apresentaram relação $\mathrm{PJ} / \mathrm{PV} 0,96 \%$ maior que os mantidos na termoneutralidade, possivelmente devido ao menor conteúdo gastrintestinal, ocasionado pelo menor consumo de ração. Os resultados da relação PC/PJ são semelhantes aos obtidos por DIVIDICH et al. (1987), para suínos em crescimento e terminação, e diferentes dos obtidos por OLIVEIRA et al. (1997).

Embora os animais mantidos no ambiente de calor 
Tabela 3 - Relações peso jejum/peso vivo (PJ/PV) e peso carcaça/peso jejum (PC/PJ) e taxas de deposição de proteína e gordura na carcaça de suínos machos castrados dos 30 aos $60 \mathrm{~kg}$

Table 3 - Fast weight/live weight ratios (FW/LW) and carcass weight/fast weight (CW/FW) and protein and fat deposition rates of barrows from 30 to $60 \mathrm{~kg}$

\begin{tabular}{|c|c|c|c|}
\hline \multirow[b]{2}{*}{$\begin{array}{l}\text { Variável } \\
\text { Variable }\end{array}$} & \multicolumn{2}{|c|}{$\begin{array}{c}\text { Temperatura ambiente }\left({ }^{\circ} \mathrm{C}\right) \\
\text { Environment temperature }\end{array}$} & \multirow[b]{2}{*}{$\alpha$} \\
\hline & 21 & 32 & \\
\hline $\begin{array}{l}\text { Relação PJ } / \mathrm{PV}(\mathrm{kg} / \mathrm{kg}) \\
\text { FW/LW ratio }\end{array}$ & $93,6 \pm 1,92$ & $94,5 \pm 1,27$ & 0,01 \\
\hline $\begin{array}{l}\text { Relação PC/PJ }(\mathrm{kg} / \mathrm{kg}) \\
C W / F W \text { ratio } \\
\text { Taxa de deposição na } \\
\text { Deposition carcass rate }\end{array}$ & $76,89 \pm 1,75$ & $76,91 \pm 1,42$ & NS \\
\hline $\begin{array}{l}\text { Proteína }(\mathrm{g} / \text { dia }) \\
\text { Protein }(g / \text { day })\end{array}$ & $81 \pm 8,6$ & $92 \pm 9,8$ & 0,01 \\
\hline $\begin{array}{l}\text { Gordura (g/dia) } \\
\text { Fat (g/day) }\end{array}$ & $238 \pm 51,4$ & $187 \pm 46,2$ & 0,01 \\
\hline
\end{tabular}

tenham apresentado menor CPD, a taxa de deposição de proteína (TDP) diária na carcaça aumentou $(\mathrm{P}<0,01)$ em 13,6\% (Tabela 3). Estes resultados podem ser atribuídos à redução observada no tamanho dos órgãos internos (Tabela 4) e à menor relação CPD/TDP dos animais expostos ao calor, sugerindo redução na exigência de proteína para a mantença desses animais.

Resultados similares de deposição de proteína na carcaça foram verificados em suínos em terminação (STAHLY e CROMWELL, 1979) e em leitões dos 15 aos $30 \mathrm{~kg}$ (OLIVEIRA et al., 1997). Por outro lado, STAHLY et al. (1979) e SCHENCK et al. (1992) não verificaram variação na TDP da carcaça dos animais, em razão da temperatura ambiente.

Verificou-se variação $(\mathrm{P}<0,01)$ entre as taxas de deposição de gordura (TDG) diária, em que os animais mantidos no ambiente quente apresentaram TDG 21,4\% menor que os da termoneutralidade (Tabela 3). Segundo Fialho e Cline (1988), citados por FIALHO (1994), a retenção de energia pelo suíno é reduzida quando da exposição a temperaturas ambientes acima de $29^{\circ} \mathrm{C}$. CLOSE et al. (1978) observaram que os valores máximos estimados de deposição de gordura foram obtidos à temperatura ambiente de $20 \mathrm{a} 25^{\circ} \mathrm{C}$, associada à maior retenção de energia.

Os resultados de TDG verificados neste trabalho podem ser explicados pelo menor consumo de energia, associado à alta temperatura ambiente (SPEER, 1991), e confirmam as observações de STAHLY e CROMWELL (1979), DIVIDICH et al. (1980), CLOSE e STANIER (1984) e CAMPBELL e TAVERNER (1988).

Os valores de pesos absolutos e relativos de órgãos internos dos animais são apresentados na Tabela 4. Não se observou efeito de interação entre temperatura ambiente e níveis de ED da ração. Observou-se redução $(\mathrm{P}<0,01 ; \mathrm{P}<0,05)$ nos pesos absolutos dos órgãos avaliados, com exceção do estômago, que foram de 4,9 (intestino delgado) a $11,4 \%$ (rins) menores nos animais submetidos ao calor. Os pesos relativos dos órgãos foram mais leves nos animais submetidos ao calor, com redução variando de 7,4 (coração) a 16,8\% (pulmões). Resultados similares foram observados em leitões dos 15 aos 64 dias de idade (DAUNCEY et al., 1983), fêmeas com $70 \mathrm{~kg}$ (LOPEZ et al., 1994), machos castrados dos 40 aos $100 \mathrm{~kg}$ (NIENABER et al., 1996) e leitões dos 15 aos $30 \mathrm{~kg}$ (OLIVEIRA et al. 1997).

DAUNCEY et al. (1983) e BIKKER et al. (1995) verificaram relação entre peso de órgãos e consumo de energia, com diferenças nos pesos dos órgãos ocorrendo a partir de variação no consumo de energia acima de $15 \%$. Analisando os resultados deste trabalho, verificou-se diferença no consumo de energia de $13,1 \%$, o que permite concluir que a variação no peso dos órgãos foi atribuída somente à temperatura ambiente.

A redução nos pesos de órgãos dos animais mantidos em ambiente quente, provavelmente, devese à tentativa de reduzir a produção de calor pelos órgãos metabolicamente ativos (ZHAO et al., 1995).

As variáveis fisiológicas de freqüência respiratória e temperatura retal tomadas de manhã (Tabela 5) aumentaram $(\mathrm{P}<0,01)$ nos animais submetidos ao estresse de calor, mas a temperatura retal à tarde não variou entre os ambientes. Embora tenha sido observado diferença estatística $(\mathrm{P}<0,01)$ na temperatura retal tomada pela manhã entre ambientes, a pequena variação de $0,1^{\circ} \mathrm{C}$ não foi suficiente para caracterizar ineficiência dos processos 
TAVARES et al.

Tabela 4 - Pesos absolutos e relativos, expressos como porcentagem da carcaça, dos órgãos internos de suínos machos castrados dos 30 aos $60 \mathrm{~kg}$

Table 4 - Absolute and relative weights, expressed as carcass percentage of internal organs of barrow from 30 to $60 \mathrm{~kg}$

\begin{tabular}{|c|c|c|c|}
\hline \multirow[b]{2}{*}{$\begin{array}{l}\text { Variável } \\
\text { Variable }\end{array}$} & \multicolumn{3}{|c|}{$\begin{array}{c}\text { Temperatura ambiente }\left({ }^{\circ} \mathrm{C}\right) \\
\text { Environment temperature }\end{array}$} \\
\hline & 21 & 32 & $\alpha$ \\
\hline \multicolumn{4}{|l|}{ Peso absoluto (g) } \\
\hline \multicolumn{4}{|l|}{ Absolute weight } \\
\hline $\begin{array}{l}\text { Fígado } \\
\text { Liver }\end{array}$ & $1224 \pm 110,6$ & $1142 \pm 117,4$ & 0,01 \\
\hline $\begin{array}{l}\text { Pulmões } \\
\text { Lungs }\end{array}$ & $490 \pm 82,1$ & $406 \pm 52,2$ & 0,01 \\
\hline $\begin{array}{l}\text { Estômago } \\
\text { Stomach }\end{array}$ & $346 \pm 28,1$ & $342 \pm 33,8$ & NS \\
\hline $\begin{array}{l}\text { Rins } \\
\text { Kidneys }\end{array}$ & $246 \pm 23,4$ & $218 \pm 19,7$ & 0,05 \\
\hline $\begin{array}{l}\text { Coração } \\
\text { Heart }\end{array}$ & $235 \pm 22,3$ & $224 \pm 17,3$ & 0,01 \\
\hline $\begin{array}{l}\text { Intestino delgado } \\
\text { Small intestine }\end{array}$ & $1241 \pm 123,8$ & $1180 \pm 98,2$ & 0,01 \\
\hline Peso relativo (\%) & & & \\
\hline $\begin{array}{l}\text { Relative weight } \\
\text { Fígado }\end{array}$ & $2,84 \pm 0,29$ & $2,61 \pm 0,31$ & 0,01 \\
\hline $\begin{array}{l}\text { Liver } \\
\text { Pulmões } \\
\text { Lungs }\end{array}$ & $1,13 \pm 0,21$ & $0,94 \pm 0,14$ & 0,01 \\
\hline $\begin{array}{l}\text { Estômago } \\
\text { Stomach }\end{array}$ & $0,81 \pm 0,08$ & $0,78 \pm 0,07$ & NS \\
\hline $\begin{array}{l}\text { Rins } \\
\text { Kidneys }\end{array}$ & $0,57 \pm 0,06$ & $0,49 \pm 0,06$ & 0,01 \\
\hline $\begin{array}{l}\text { Coração } \\
\text { Heart }\end{array}$ & $0,54 \pm 0,06$ & $0,50 \pm 0,05$ & 0,01 \\
\hline $\begin{array}{l}\text { Intestino delgado } \\
\text { Small intestine }\end{array}$ & $2,88 \pm 0,31$ & $2,69 \pm 0,29$ & 0,01 \\
\hline
\end{tabular}

Tabela 5 - Variáveis fisiológicas de suínos machos castrados dos 30 aos 60 kg Table 5 - Physiological variables of barrow from 30 to $60 \mathrm{~kg}$

\begin{tabular}{|c|c|c|c|}
\hline \multirow[b]{2}{*}{ Variável } & \multicolumn{3}{|c|}{$\begin{array}{c}\text { Temperatura ambiente }\left({ }^{\circ} \mathrm{C}\right) \\
\text { Environment temperature }\end{array}$} \\
\hline & 21 & 32 & $\alpha$ \\
\hline \multicolumn{4}{|l|}{ Variable } \\
\hline Freqüiência respiratória (mov/min) & $44 \pm 7,9$ & $82 \pm 14,1$ & 0,01 \\
\hline Respiratoryfrequency & & & \\
\hline Temperatura retal manhã $\left({ }^{\circ} \mathrm{C}\right)^{*}$ & $39,6 \pm 0,17$ & $39,7 \pm 0,22$ & 0,01 \\
\hline Rectal temperature in the morning & & & \\
\hline Temperatura retal tarde $\left({ }^{\circ} \mathrm{C}\right)^{*}$ & $39,6 \pm 0,21$ & $39,7 \pm 0,20$ & NS \\
\hline Rectal temperature in the evening & & & \\
\hline
\end{tabular}

termorregulatórios, sendo, portanto, as temperaturas retais consideradas biologicamente iguais.

Do mesmo modo, a diferença $(\mathrm{P}<0,01)$ de apenas $0,09^{\circ} \mathrm{C}$ observada na temperatura retal entre os períodos da manhã e da tarde, no ambiente de $21^{\circ} \mathrm{C}$, não foi considerada biologicamente relevante, em razão das condições experimentais de temperatura ambiente relativamente constante.
Resultados semelhantes de freqüência respiratória foram obtidos por CLOSE (1971), CHRISTON (1988), LOPEZ et al. (1991) e OLIVEIRA et al. (1997) para suínos em diferentes fases de crescimento. Segundo CHRISTON (1988) e FIALHO (1994), o aumento da taxa respiratória propicia aumento na dissipação de calor por evaporação através do trato respiratório dos animais estressados pelo calor, o que, 
associado a outros processos (redução no peso dos órgãos), provavelmente ocasionou a manutenção da temperatura retal dos animais expostos ao calor dentro da faixa de 39,0 a $40,0^{\circ} \mathrm{C}$, considerada normal para os suínos (BIANCA, 1968).

Portanto, pode-se concluir que os processos fisiológicos de termorregulação utilizados pelos suínos machos castrados mantidos no ambiente de estresse de calor foram eficientes na manutenção da homeotermia.

\section{Conclusões}

Os animais expostos ao calor apresentaram menor ganho de peso, menor consumo de ração e pior eficiência de utilização do alimento, enquanto a eficiência de utilização da proteína e a taxa de deposição de proteína foram maiores, em relação aos animais mantidos no ambiente termoneutro.

\section{Referências Bibliográficas}

BIKKER, P., KARABINAS, V., VERSTENGEN, M.W.A, CAMPBELL, R.G. 1995. Protein and lipid accretion in body components of growing gilts (20 to 45 kilograms) as affected by energy intake. J. Anim. Sci., 73(8):2355-2363.

BIANCA, W. 1968. Thermoregulation. In: HAFEZ, E.S.E. (Ed.) Adaptation of domestic animals. Philadelphia: Lea \& Febiger. p.97-118.

CAMPBELL, R.G., TAVERNER, M.R. 1988. Relationships between energy intake and protein and energy metabolism, growth and body composition of pigs kept at 14 or $32^{\circ} \mathrm{C}$ from 9 to $20 \mathrm{~kg}$. Lvstck. Prod. Sci., 18(3-4):289-303.

CLOSE, W. H. 1971. The influence of environmental temperature and plane of nutrition on heat losses from individual pigs. Anim. Prod., 13(2):295-302.

CLOSE, W.H., MOUNT, L.E., BROWN, D. 1978. The effects of plane of nutrition and environmental temperature on the energy metabolism of the growing pig. Br.J. Nutr, 40(3):423-431.

CLOSE, W.H., STANIER, M.W. 1984. Effects of plane nutrition and environmental on the growth and development of the early-weaned piglet. 2. Energy metabolism. Anim. Prod., 38(2):221-231.

CHRISTON, R. 1988. The effect of tropical ambient temperature on growth and metabolism in pigs. J. Anim. Sci., 66(12):3112-3123.

DAUNCEY,M.J., INGRAM,D.L., WALTERS, D.E. 1983.Evaluation of the effects of environmental temperature and nutrition on growth and development. J. Agric. Sci., 101(2):291-299.

DIVIDICH, J.L., NOBLET, J. 1986. Effect of dietary energy level on the performance of individually housed early-weaned piglets in relation to environmental temperature. Lvstck. Prod. Sci., 14(3):255-263.

DIVIDICH, J.L., NOBLET, J., BIKAWA, T. 1987. Effect of environmental temperature and dietary energy concentration on the performance and carcass characteristics of growingfinishing pigs fed to equal rate of gain. Lvstck. Prod. Sci., $17(3): 235-246$.

DIVIDICH, J.L., VERMOREL, M., NOBLET, J. et al. 1980. Effects of environmental temperature on heat production, energy retention and fat gain in early weaned piglets. $B r . J$. Nutr., 44(3):313-323.
DONZELE, J. L., COSTA, P. M. A., ROSTAGNO, H. S. 1992. Efeitos de níveis de enrgia digestíveis na composição da carcaça de suínos de cinco a quinze quilos. R. Soc. Bras. Zootec., 21(6):1100-1106.

FIALHO, E.T. Influência da temperatura ambiental sobre a utilização da proteína e energia em suínos em crescimento e terminação. In: SIMPÓSIO LATINO-AMERICANO DE NUTRIÇÃO DE SUÍNOS, 1994, São Paulo. Anais... São Paulo: CBNA, 1994. p.63-83.

FORBES, J.M. 1995. Voluntary food intake and diet selection in farm animals. CAB International. 531p.

JENSEN, A.H. 1991. Environment and management factors that influence swine nutrition. In: MILLER, E.R., ULLREY, E.D., LEWIS, A.J. (Eds.) Swine nutrition. ButterworthHeinemann. p.387-399.

LOPEZ, J., JESSE, G.W., BECKER, B.A. 1991. Effects of temperature on the performance of finishing swine. I. Effects of a hot, diurnal temperature on average daily gain, feed intake and feed efficiency. J. Anim. Sci., 69(5):1843-1849.

LOPEZ, J., GOODBAND, R.D., ALLEE, G.L. et al. 1994. The effects of diets formulated on an ideal protein basis on growth performance, carcass characteristics, and thermal alance of finishing housed in a hot, diurnal environment. J. Anim. Sci., 72(2):367-379.

NIENABER, J.A., HAHN, G.L., McDONALD, T.P. et al. 1996. Feeding pattern and swine performance in hot environments. Trans. ASAE, 39(1):195-202.

OLIVEIRA, R.F.M., DONZELE, J.L., FREITAS, R.T.F. 1997. Efeito da temperatura sobre o desempenho e sobre os parâmetros fisiológicos e hormonais de leitões consumindo dietas com diferentes níveis de energia. R. Bras. Zootec., 26(6):1174-1182.

ROSTAGNO, H.S., SILVA, D.J., FONSECA, J.B. et al. 1992. Composição de alimentos e exigências nutricionais de aves e suínos (tabelas brasileiras). 1.ed. Viçosa - MG: UFV, Impr. Univ. 59p.

SCHENCK, B.C., STAHLY, T.S., CROMWELL, G.L. 1992. Interactive effects of thermal environmental and dietary lisine and fat levels on rate, efficiency, and composition of growth of weanling pigs. J. Anim. Sci., 70(12):3791-3802.

SILVA, D.J. 1990. Análise de alimentos (Métodos químicos e biológicos). Viçosa - MG: UFV, Impr. Univ. 166p.

SPEER, V.C. 1991. Maximizing lean tissue growth: genetic, nutritional, and environmental factors. In: MILLER, E.R., ULLREY, E.D., LEWIS, A.J. (Eds.) Swine nutrition. Butterworth-Heinemann. p.91-102.

STAHLY, T.S., CROMWELL, G.L. 1979. Effect of environmental temperature and dietary fat supplementation on the performance and carcass characteristics of growing and finishing swine. J. Anim. Sci., 49(6):1478-1488.

STAHLY, T.S., CROMWELL, G.L., AVIOTTI, M. P. 1979. The effect of environmental temperature and dietary lysine source and level on the performance and carcass characteristics of growing swine. J. Anim. Sci., 49(5):1242-1251.

STAHLY, T.S., CROMWELL, G.L. 1986. Responses to dietary additions of fier (alfafa meal) in growing pigs housed in a cold, warm or hot thermal environment. J. Anim. Sci., 63 (6): $1870-1876$.

UNIVERSIDADE FEDERAL DE VIÇOSA. 1982. Central de Processamento de Dados - UFV - CPD. SAEG. Sistemas para análises estatísticas e genéticas. Viçosa, MG. 59p.

ZHAO, X., JORGENSEN, H., EGGUM,B. 1995. The influence of dietary fibre on body composition, visceral organ weight, digestibility and energy balance in rats housed in different thermal environments. Br. J. Nutr., 73(5):687-699.

Recebido em: 22/02/99 Aceito em: 27/06/99 